\title{
Pakistan to work with India, Afghan on water management
}

By PTI | Updated: May 03, 2017, 11.52 AM IST

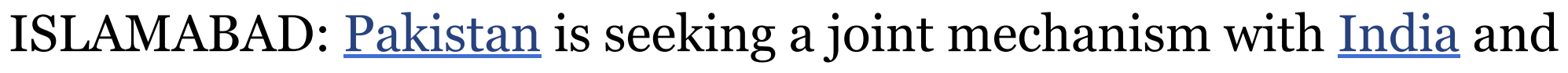
Afghanistan for watershed management and trans-boundary aquifer sharing to minimise the negative impact of development projects.

Watershed management relates to the land and water management practices that can help protect and improve the water quality, while aquifer refers to the underground layer of rock or minerals that holds water.

This is part of Pakistan's National Water Policy, which also seeks to ensure 100 per cent metering of urban water uses, including drinking and sanitation, the Dawn reported.

The policy finalised by the government and the provinces was on the agenda of the Council of Common Interests yesterday, but could not be taken up due to Prime Minister Nawaz Sharif's political engagements, the daily reported.

The policy concedes that "the Indus Waters Treaty provided a mechanism for water-sharing with India, but its provisions on hydropower development across the Line of Control had the potential of threatening Pakistan's water availability during low-flow periods," the daily said.

The treaty also does not provide for minimum environmental flows downstream of the international boundary for the Eastern Rivers -- whose waters lie with India -- exposing the population living downstream to serious hazards, it said.

"The regional mechanisms involving more than two neighbours shall be explored for a viable solution to Pakistan's growing vulnerability to hydro- 
meteorological disasters, owing to trans-border winter releases and stoppages at critical times of monsoon and during rabi and kharif planting seasons," it said.

A mechanism shall also be worked out for sharing of trans-boundary aquifers and joint watershed management, including sharing of real-time water flow information.

A study would also be conducted to analyse the impact of challenges arising out of developments on the western rivers and examine measures to minimise the impact within the framework of the Indus Waters Treaty and international water laws.

The new policy acknowledged that water was a "highly under-priced commodity" and its prevailing cost recovery through cess was hardly able to meet a fraction of the operating and maintenance cost of the irrigation infrastructure.

The policy said that full financial sustainability shall be ensured to provide progressively safe drinking water and sanitation facilities.

"This shall be facilitated by effective reduction in wastage, theft and reduction of non-revenue water and 100 per cent metering" while providing safety nets for impoverished communities.

A mechanism would be put in place by all the federal and provincial governments to charge all types of water use in order to ensure the recovery of the cost of repair and maintenance of water infrastructure. 